\title{
Using the DEMATEL method to identify key reasons for mathematics support
}

\author{
$\underline{\text { M. Dzator }}^{\mathrm{a}, \mathrm{c}}$ and J.Dzator ${ }^{\mathrm{b}, \mathrm{c}}$ \\ ${ }^{a}$ SAE, Central Queensland University, Mackay; ${ }^{b}$ The University of Newcastle, NSW \\ ${ }^{c}$ Australia Africa Universities Network Partner \\ Email:m.dzator@cqu.edu.au
}

\begin{abstract}
The Decision Making and Trial Evaluation Laboratory (DEMATEL) is considered as a useful and effective method for structural modeling which is comprehensively based on matrices. It is a commonly used method for modelling relationship between variables. DEMATEL has been applied in many areas such as project management, environmental engineering, social science, facility location problems and education for investigating relationship among variables. DEMATEL reveals the relationship and the severity of the effects of factors on each other. This method uses matrices and diagrams for visualizing the structure of complicated causal relationships.

There is an increasing concern worldwide about the level of mathematical skills that is necessary for students to pursue their studies successfully at universities. Many countries including Australia are currently increasing resources for improvement in the uptake of mathematics in secondary or high schools. In the short term however, there are numerous students enrolled in universities and other tertiary institutions who lack mathematical skills and, in some cases, severely. Since most university courses require some level of mathematics literacy, the need to find solutions to the problem has become important for many universities in the world. An effective way to address this is to engage students, by offering the study of mathematics at Mathematics Learning Support Centres. Fundamentally, learning support programs and especially in mathematics provide extra assistance to students in current enrolment in a university. In order to improve or maximise delivery of service at Mathematics Learning Support Centres, an assessment of the reasons for using the centres is required.

Ten reasons for seeking mathematics support were identified from literature review and interview with six experts comprising three mathematics learning advisers and students. The interrelationships among the reasons were considered in the application of DEMATEL method to determine the key reasons for seeking mathematics support. The DEMATEL method has identified that 'improving students' confidence in mathematics; helping students understand mathematics elements of course and reducing difficulty of solving mathematics problems as the top three important reasons for seeking mathematics help at a mathematics support centre at Central Queensland University (CQU).
\end{abstract}

Keywords: DEMATEL, structural model, influence, mathematics support, reasons 


\section{INTRODUCTION}

The establishment of Mathematics Learning Support Centres (MLSCs) at universities is an effective way to support students and minimise the decline of mathematics knowledge for successful education in the tertiary setting. Mathematics Learning Support (MLS) can be described as any extra non-credit, optional, noncompulsory program that helps students in developing their mathematical skills during their enrolled study in a degree course (MacGillivray, 2008). There are a number of reasons for students using MLSCs for MLS. A study by O'Sullivan et al. (2014) have analysed students' comments and listed some reasons why students sought MLS. Perkin et al. (2007) also examined the reasons why there are availability of MLSCs. They determined the most frequent reason for students' attendance at the MLSC for MLS in the study. Even though there were discussions regarding the reasons for seeking MLS at MSLCs in the literature (Matthews, 2013) none of the studies have examined the reasons in detail. Literature review and expert opinion were used to determine the reasons for seeking mathematics support in this study. There is no study who have ranked the reasons in the order of importance. Ranking the reasons will help the students and the Mathematics Learning Advisers (MLAs) to focus on key objectives or reasons when seeking MLS or when delivering MLS respectively. This paper will use a decision making model (DEMATEL) to rank the reasons for seeking MLS to enable us to identify important reasons necessary to improve mathematical skills. The objective of this paper is to use DEMATEL to identify key reasons for seeking mathematics support in universities. To the best of our knowledge, this is the first paper that has applied DEMATEL to MLS. The remainder of the paper is organized as follows. Section 2 discusses DEMATEL method. The methodology is presented in Section 3 and we have the results and discussions presented in Section 4. We conclude the paper in Section 5.

\section{DEMATEL METHOD}

The Decision Making and Trial Evaluation Laboratory (DEMATEL) method was developed in Switzerland by Gabus and Fontel $(1972,1973)$ to be used to serve as a tool that would make it possible to solve complex problems and to analyse a variety of causal links. For example, a set of complex problem have a set of elements which have binary relation with each other. It is a commonly used method for modelling relationship between variables. DEMATEL which involve five steps are describe as follows:

Step 1: Generate the direct relation matrix. The matrix represents the aggregate influence scores for various variables or factors. The rating of 0 (No influence), 1 (Low influence), 2 (Medium influence), 3 (High influence) and 4 (Very high influence) among the various factors or variables is done by experts. The average of the matrices which represent the rating from each expert are determined which will result in a square matrix $A$ with zero at the principal diagonal. $A=\left[a_{i j}\right]_{n x n}$ where, $a_{i j}$ represents the degree which factor $i$ impacts factor j. That is

$$
A=\frac{1}{N} \sum_{k=1}^{N} a_{i j}^{k}, \text { where } N \text { is the number of experts. }
$$

Step 2: Normalize the direct relation matrix. The normalized direct relation matrix $B$ is obtained as follows

$$
B=\frac{A}{\max \left[\max \sum_{i=1}^{n} a_{i j}, \max \sum_{j=1}^{n} a_{i j}\right]}, i, j \in\{1,2, \ldots, n\}
$$

That is divide matrix $A$ by the maximum of the sum of rows and sum of columns.

Step 3: Develop the total relation matrix $C$ from the normalized direct relation matrix $B$ as follows. The total relation matrix $C$ in which $I$ is the identity matrix and $B^{m}$ is $m$-indirect influence is obtained by

$$
C=\left[c_{i j}\right]_{n x n}=B+B^{2}+\ldots+B^{m}=B(I-B)^{-1} \text { when } m \rightarrow \infty
$$

Step 4: Produce a causal diagram by using the sum of rows $D$ and sum of the columns $E$

$$
D=\left[d_{i j}\right]_{n x 1}=\left[\sum_{j=1}^{n} c_{i j}\right]_{n x 1}, E=\left[e_{i j}\right]_{1 x n}=\left[\sum_{i=1}^{n} c_{i j}\right]_{1 x n}
$$

The horizontal axis $(D+E)$ represents the importance of the variables whereas the vertical axis $(D-E)$ shows the cause and effect relationships. The variables with positive $(D-E)$ values are the cause factors whereas those 
with negative are effect factors. The sum of $i$ th row $D$ is the causal influence and the sum of the $j$ th column $E$ is the effect influence of the total relation matrix $C$.

Step 5: Depict structural relation between variables

The structural relation amongst variables is shown through an inner dependence matrix by retaining only those variables whose effect in the matrix $C$ is greater than the threshold value $\mu$ can be given by the experts, based on literature review or obtained by averaging the values of $C$ matrix elements. The use of the threshold to simplify the total relation matrix is to filter out the variables having negligible effects from the total relation matrix $C$. The matrix obtained by setting the values which are less than the threshold value is known as the inner dependency matrix.

There are a number of studies with detailed discussion of the steps who applied DEMATEL to examine university problems. A DEMATEL method was used by Chen (2016) to validate the service factors of an academic library in Taiwan university. Empathy was determined to be the most important factor in services provided at the academic library. Ranjan et al. (2015) also used DEMATEL method to rank 16 departments of an Indian university with Electrical Engineering department ranked as number one. The other studies who have applied DEMATEL method to examine university problems include Hwang et al. (2016); Cheng et al. (2016); Kiakojuri et al. (2015). The detail review regarding DEMATEL method is discussed in Si et al. (2018).

\section{METHODOLOGY}

The first step of the methodology involves selection of 'reasons for seeking MLS' using literature review and discussion with MLAs and regular students at the ALC for MLS. Teng (2002) proposed that 5 to 15 experts are appropriate for group decision making. Therefore, six experts were used for the determination of the level of influence among the reasons. The second step involves classifying the reasons into a matrix form. The third step involves the application of DEMATEL. DEMATEL is used as a solution methodology since it is best suited for analysing interrelationships among the reasons. It will also help us to identify the important reasons for seeking MLS.

\subsection{Reasons (Factors) for seeking MLS}

The list of 10 reasons for using MLS was obtained from the results of the literature (O'Sullivan et al., 2014; Perkin et al., 2007, Matthew et al., 2013) and by brainstorming. There was further discussion with three MLAs together with three regular students at CQU in Australia. All the reasons were retained after the discussion and presented as follows: R1. To help understand mathematics elements of courses. R2. To improve mathematics background of students. R3. To reduce the difficulty of solving mathematics problems. R4. To reduce mathematical gaps of students entering university. R5. To improve students' confidence in mathematics. R6. To reduce attrition at universities. R7. To help students' learning. R8. To increase students' engagement at universities. R9. To improve students' assignment marks. R10. To improve students' examination pass rates.

\section{RESULTS AND DISCUSSIONS}

The results from the experts (MLAs and students who used MLSCs) are presented below.

Step 1: The average matrix is obtained by adding all the six matrices from the experts and dividing by 6 using Microsoft Excel. Matrix A is obtained using Equation 1 
M. Dzator and J. Dzator, Using the DEMATEL Method to Identify Key Reasons for Mathematics Support

$$
\left[\begin{array}{llllllllll}
0.000 & 3.333 & 3.333 & 3.500 & 3.500 & 2.500 & 2.333 & 2.500 & 2.833 & 3.000 \\
3.500 & 0.000 & 2.833 & 3.833 & 3.167 & 2.667 & 3.167 & 2.333 & 2.833 & 2.833 \\
3.667 & 3.500 & 0.000 & 2.833 & 3.000 & 2.333 & 3.667 & 2.667 & 3.000 & 3.167 \\
2.500 & 2.833 & 2.667 & 0.000 & 3.500 & 2.500 & 2.667 & 2.333 & 2.833 & 2.667 \\
3.500 & 2.667 & 2.667 & 2.833 & 0.000 & 2.333 & 3.000 & 3.167 & 3.167 & 3.167 \\
1.667 & 1.833 & 1.667 & 1.667 & 2.000 & 0.000 & 1.833 & 2.500 & 2.333 & 2.333 \\
3.000 & 3.167 & 3.000 & 3.000 & 3.500 & 2.500 & 0.000 & 2.667 & 3.333 & 3.167 \\
2.667 & 2.333 & 2.500 & 2.167 & 2.833 & 3.000 & 3.167 & 0.000 & 2.667 & 2.667 \\
2.833 & 2.500 & 3.000 & 3.000 & 3.167 & 2.667 & 2.667 & 2.167 & 0.000 & 3.500 \\
2.333 & 2.500 & 2.833 & 2.500 & 3.333 & 3.500 & 2.667 & 2.333 & 3.167 & 0.000
\end{array}\right]
$$

Figure 1. Average Matrix A

Step 2: Matrix A is divided by max (sum of rows, sum of columns) = Matrix A divided by max (27.833, 28.000). That is Matrix A is divided by 28.000. Matrix B is obtained using Equation 2

$\left[\begin{array}{llllllllll}0.000 & 0.119 & 0.119 & 0.125 & 0.125 & 0.089 & 0.083 & 0.089 & 0.101 & 0.107 \\ 0.125 & 0.000 & 0.101 & 0.137 & 0.113 & 0.095 & 0.113 & 0.083 & 0.101 & 0.101 \\ 0.131 & 0.125 & 0.000 & 0.101 & 0.107 & 0.083 & 0.131 & 0.095 & 0.107 & 0.113 \\ 0.089 & 0.101 & 0.095 & 0.000 & 0.125 & 0.089 & 0.095 & 0.083 & 0.101 & 0.095 \\ 0.125 & 0.095 & 0.095 & 0.101 & 0.000 & 0.083 & 0.107 & 0.113 & 0.113 & 0.113 \\ 0.060 & 0.065 & 0.060 & 0.060 & 0.071 & 0.000 & 0.065 & 0.089 & 0.083 & 0.083 \\ 0.107 & 0.113 & 0.107 & 0.107 & 0.125 & 0.089 & 0.000 & 0.095 & 0.119 & 0.113 \\ 0.095 & 0.083 & 0.089 & 0.077 & 0.101 & 0.107 & 0.113 & 0.000 & 0.095 & 0.095 \\ 0.101 & 0.089 & 0.107 & 0.107 & 0.113 & 0.095 & 0.095 & 0.077 & 0.000 & 0.125 \\ 0.083 & 0.089 & 0.101 & 0.089 & 0.119 & 0.125 & 0.095 & 0.083 & 0.113 & 0.000\end{array}\right]$

Figure 2. Normalised Direct Relation Matrix B

Step 3: Multiply Matrix B by the inverse of the identity matrix I minus Matrix B. Matrix C is obtained using Equation 3

$\left[\begin{array}{llllllllll}0.926 & 0.998 & 0.994 & 1.027 & 1.113 & 0.949 & 0.984 & 0.907 & 1.034 & 1.049 \\ 1.046 & 0.901 & 0.988 & 1.046 & 1.114 & 0.962 & 1.016 & 0.910 & 1.043 & 1.054 \\ 1.078 & 1.038 & 0.922 & 1.044 & 1.138 & 0.978 & 1.057 & 0.944 & 1.075 & 1.091 \\ 0.933 & 0.911 & 0.902 & 0.841 & 1.032 & 0.879 & 0.920 & 0.836 & 0.957 & 0.963 \\ 1.026 & 0.968 & 0.964 & 0.996 & 0.990 & 0.934 & 0.992 & 0.917 & 1.032 & 1.043 \\ 0.685 & 0.667 & 0.660 & 0.678 & 0.747 & 0.591 & 0.678 & 0.643 & 0.717 & 0.725 \\ 1.039 & 1.009 & 1.000 & 1.028 & 1.130 & 0.964 & 0.922 & 0.926 & 1.065 & 1.071 \\ 0.916 & 0.876 & 0.877 & 0.891 & 0.989 & 0.874 & 0.913 & 0.740 & 0.931 & 0.941 \\ 0.972 & 0.930 & 0.941 & 0.967 & 1.055 & 0.913 & 0.949 & 0.857 & 0.896 & 1.081 \\ 0.939 & 0.912 & 0.918 & 0.934 & 1.039 & 0.920 & 0.931 & 0.847 & 0.979 & 0.888\end{array}\right]$

Figure 3. Total Relation Matrix C

Step 4: Sum the rows and columns of Matrix C to obtained D and E using Equations 4 and 5 respectively. The results are shown in Tables 1 . 
Table 1. The sum and difference of influences for the ten reasons

\begin{tabular}{|l|l|l|l|l|l|l|}
\hline Reasons & Row Sum D & Column Sum E & D+E & D-E & Rank & Cause or Effect \\
\hline R1 (r1) & 9.982 & 9.559 & 19.541 & 0.423 & 2 & Cause \\
\hline R2 (r2) & 10.082 & 8.211 & 19.293 & 0.871 & 5 & Cause \\
\hline R3 (r3) & 10.365 & 9.167 & 19.532 & 1.198 & 3 & Cause \\
\hline R4 (r4) & 9.173 & 9.453 & 18.626 & -0.280 & 8 & Effect \\
\hline R5 (r5) & 9.863 & 10.346 & 20.209 & -0.483 & 1 & Effect \\
\hline R6 (r6) & 6.700 & 8.965 & 15.754 & -2.175 & 10 & Effect \\
\hline R7 (r7) & 10.154 & 9.362 & 19.516 & 0.792 & 4 & Cause \\
\hline R8 (r8) & 8.948 & 8.527 & 17.475 & 0.421 & 9 & Cause \\
\hline R9 (r9) & 9.499 & 9.730 & 19.229 & -0.231 & 6 & Effect \\
\hline R10 (r10) & 9.309 & 9.844 & 19.153 & -0.535 & 7 & Effect \\
\hline
\end{tabular}

Step 5: The Inner Dependence Matrix is obtained by omitting values which are less than the threshold of 0.942 from Matrix $\mathrm{C}$. The average of the values of Matrix $\mathrm{C}$ is used as the threshold for the study.

$\left[\begin{array}{llllllllll}0.000 & 0.998 & 0.994 & 1.027 & 1.113 & 0.949 & 0.984 & 0.000 & 1.034 & 1.049 \\ 1.046 & 0.000 & 0.988 & 1.046 & 1.114 & 0.962 & 1.016 & 0.000 & 1.043 & 1.054 \\ 1.078 & 1.038 & 0.000 & 1.044 & 1.138 & 0.978 & 1.057 & 0.944 & 1.075 & 1.091 \\ 0.000 & 0.000 & 0.000 & 0.000 & 1.032 & 0.000 & 0.000 & 0.000 & 0.957 & 0.963 \\ 1.026 & 0.968 & 0.964 & 0.996 & 0.990 & 0.000 & 0.992 & 0.000 & 1.032 & 1.043 \\ 0.000 & 0.000 & 0.000 & 0.000 & 0.000 & 0.000 & 0.000 & 0.000 & 0.000 & 0.000 \\ 1.039 & 1.009 & 1.000 & 1.028 & 1.130 & 0.964 & 0.000 & 0.000 & 1.065 & 1.071 \\ 0.000 & 0.000 & 0.000 & 0.000 & 0.989 & 0.000 & 0.000 & 0.000 & 0.000 & 0.000 \\ 0.972 & 0.000 & 0.000 & 0.967 & 1.055 & 0.000 & 0.949 & 0.000 & 0.000 & 1.018 \\ 0.000 & 0.000 & 0.000 & 0.000 & 1.039 & 0.000 & 0.000 & 0.000 & 0.979 & 0.000\end{array}\right]$

Figure 4. Simplified Matrix Threshold is 0.942 - Inner Dependence Matrix

Table 2. Cause and Effect Reasons

\begin{tabular}{|l|l|}
\hline \multicolumn{1}{|c|}{ Cause Reasons } & \multicolumn{1}{c|}{ Effect Reasons } \\
\hline To help understand mathematics elements of courses (r1) & To reduce mathematical gaps of students entering university (r4) \\
\hline To improve mathematics background of students (r2) & To improve students' confidence in mathematics (r5) \\
\hline To reduce the difficulty of solving mathematics problems (r3) & To reduce attrition at universities (r6) \\
\hline To help students' learning (r7) & To improve students' assignment marks (r9) \\
\hline To increase students' engagement at universities (r8) & To improve students' examination pass rates (r10) \\
\hline
\end{tabular}

Table 1 shows the degree of influence of each reason over the other reasons using the total relation matrix shown in Figure 3. Reasons having the higher value of $\mathrm{D}+\mathrm{E}$ are among the reasons that have the highest degree of relationship with other reasons for seeking MLS according to the MLAs and students. The importance of the ten reasons based on $\mathrm{D}+\mathrm{E}$ (the greater the value the more important is the reason) in Table 1 are as follows: $\mathrm{r} 5>\mathrm{r} 1>\mathrm{r} 3>\mathrm{r} 7>\mathrm{r} 2>\mathrm{r} 9>\mathrm{r} 10>\mathrm{r} 4>\mathrm{r} 8>\mathrm{r} 6$. The most important reason for seeking MLS according to the experts is $\mathrm{r} 5$ which is 'to improve students' confidence in mathematics' with the value of 20.209 and the least important is $\mathrm{r} 6$ which is 'to reduce attrition at universities' with the value of 15.754. To improve students' confidence which is the most importance reason is also being influence by other reasons because is in the effect group. Table 2 shows the cause reasons and the effect reasons.

The difference between the row sum D and column sum E determines the cause group and the effect group. The reasons with positive D-E values are in the cause group while the reasons with negative values are in the effect group. The cause reasons include $\mathrm{r} 1, \mathrm{r} 2, \mathrm{r} 3, \mathrm{r} 7$ and $\mathrm{r} 8$ since $\mathrm{D}-\mathrm{E}$ is positive and the effect reasons include $\mathrm{r} 4, \mathrm{r} 5, \mathrm{r} 6, \mathrm{r} 9$ and $\mathrm{r} 10$ since D-E is negative as shown in the Table land Figure 5. The difference between the 
row sum D and column sum E determines the cause group and the effect group. The reasons with positive D$\mathrm{E}$ values are in the cause group while the reasons with negative values are in the effect group. The cause reasons include $\mathrm{r} 1, \mathrm{r} 2, \mathrm{r} 3, \mathrm{r} 7$ and $\mathrm{r} 8$ since D-E is positive and the effect reasons include $\mathrm{r} 4, \mathrm{r} 5, \mathrm{r} 6, \mathrm{r} 9$ and $\mathrm{r} 10$ since D-E is negative as shown in the Table 1 and Figure 5.

Figure 5 which is obtained by plotting D-E against D+E also confirmed the results shown in Tables 1 . Figure 5 shows that $\mathrm{r} 1, \mathrm{r} 2, \mathrm{r} 3, \mathrm{r} 7$ and $\mathrm{r} 8$ are the cause reasons while $\mathrm{r} 4, \mathrm{r} 5, \mathrm{r} 6, \mathrm{r} 9$ and $\mathrm{r} 10$ are the effect reasons. $\mathrm{r} 5$ is also the highest impact reason with a value of 20.209. The MLAs at the ALC at CQU should focus on the reasons in the cause group because focusing on these reasons while delivering MLS will improve reasons in the effect group such as improving students' confidence in mathematics and improving students' pass marks. Dzator and Dzator (2018); Wilkins (2015); Gordon and Nicholas (2012) and MacGillivray (2009) have identified in their studies that students' confidence in mathematics was improved after attendance at MLSC for MLS. This supports the findings obtained from applying DEMATEL method to determine the cause and effect reasons for seeking MLS.

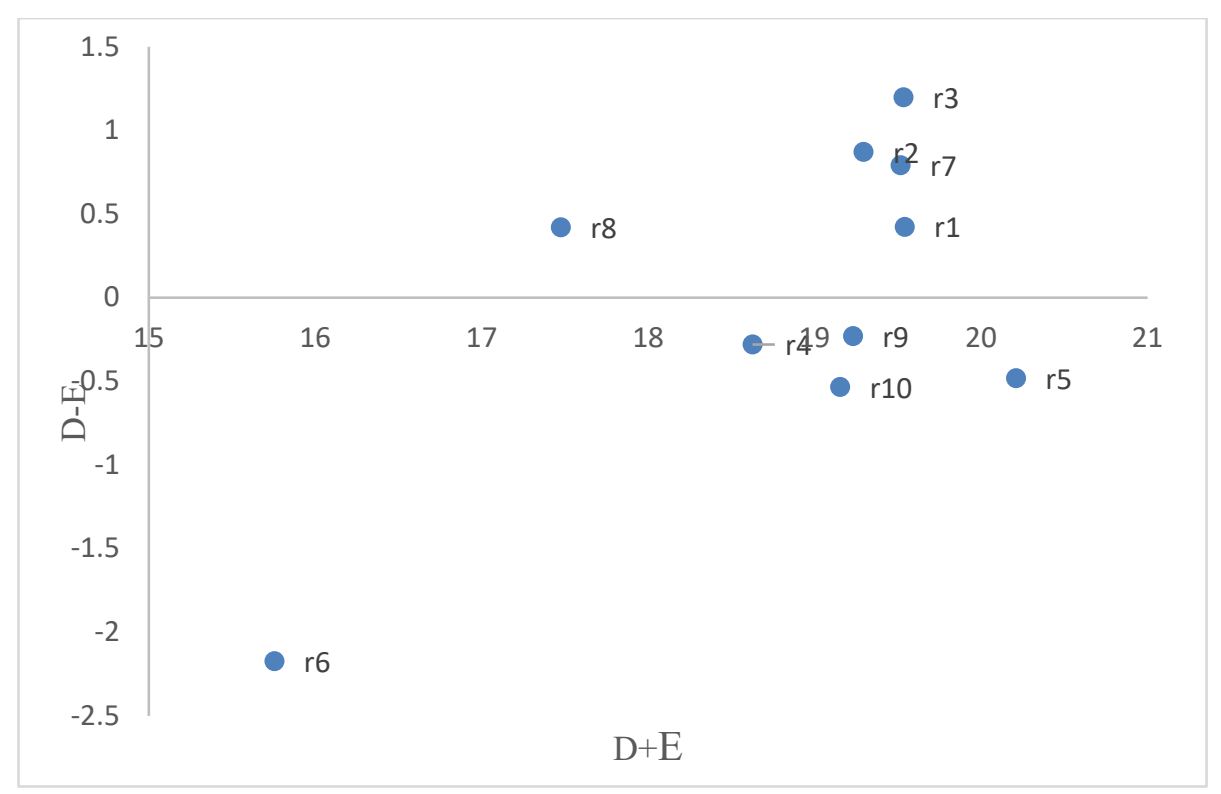

Figure 5. Prominence - Causal Diagram

The five cause reasons influence the other reasons thus they are the main diving factors for MLS. Improving students' confidence in mathematics is in the effect group and is also the most important according to the experts. Applying the cause reasons while delivering mathematics support as a MLA will have effect on the reasons in the effect group. For example, helping students to understand course elements will improve students' confidence in mathematics (Gordon, 2012; Wilkin, 2015). The remaining reasons in the cause group will have similar effect on students' confidence. For example, reducing the difficulty of soling mathematics problems with a value of 1.138 in Figure 4 is the most influential on the improvement of students' confidence in mathematics. The row sum in Table 1show the influence of a particular reason over the other reasons for seeking MLS. The higher the row sum the higher the influence over the other reasons. 'Reducing the difficulty of solving mathematics problems' with the highest row sum have maximum influence over the other reasons. This confirmed the effect of reducing the difficulty of solving mathematics problems on confidence. The column sum in Table 1 also show reasons which receive the highest effect from the other reasons. Improving students' confidence in mathematics is the column sum with the highest value of 10.346. Therefore, improving students' confidence in mathematics will have the highest effect from the other reasons for seeking MLS. The least influential on improving students' confidence as shown from Figure 4 is 'to increase students' engagement at universities' with a value of 0.989 .

\section{CONCLUSION}

In the study, we were able to identify the reasons for seeking MLS. A DEMATEL method was applied to the reasons from the literature and the ones obtained from brainstorming and discussions with MLS experts.

This study is the first that have applied DEMATEL to MLS. The top three important reasons identified in this study include 'improving students' confidence in mathematics'; helping students understand mathematics elements of course' and reducing the difficulty of solving mathematics problems. 'Improving students' 
confidence' is the most important reason according to the study. This reason is also highly influenced by the other reasons. For example, 'helping students to understand mathematics elements of their courses' or 'reducing the difficulty of solving mathematics problems' will help improve students' confidence in mathematics. This is confirmed by the results from the study

The identification of the key reasons using DEMATEL method will help MLAs and students target these key objectives of seeking MLS which will enable students to have maximum gain from MLS. This will also help the MLAs to have a desirable outcome in the delivery of MLS services.

The proposed study has limitations which need to be investigated for future research. Suggestions for future research includes:

- Increase the number of experts for the DEMATEL method

- Compare the results obtained from MLAs and the students' that sought MLS

More reasons for seeking MLS could also be explored for future research.

\section{REFERENCES}

Chen, Y.T. (2016) Applying the DEMATEL approach to identify the focus of library service quality: a case study of a Taiwanese academic library, The Elec Lib., 34(2): 315 - 331.

Cheng, C, Tsai, M, and Lin C. (2016). Quality education service: put yourself in their shoes, Current Issues in Tourism, 19(11): $1120-1135$.

Dzator, M. and Dzator, J. (2018). The impact of mathematics and statistics support at the Academic Learning Centre, Central Queensland University. https://academic.oup.com/teamat/advance-article/doi/10.1093/teamat/hry016/5088047

Gabus, A. and Fontela, E. (1972). World problems, an invitation to further thought within the framework of DEMATEL, Battelle Geneva Research Centre, Geneva, Switzerland.

Gabus, A, Fontela, E. (1973). Perceptions of the world problematique: Communication procedure, communicating with those bearing collective responsibility (DEMATEL report no. 1), Battelle Geneva Research Centre, Geneva, Switzerland.

Gordon, S., \& Nicholas, J. (2012) Measuring the impact of early mathematics support for student enrolled in an introductory calculus unit of study. In M. Sharma, \& A. Yeung (Eds.), Proceedings of the Australian Conference on Science and Mathematics Education, (pp. 99-104). Sydney, Australia: IISME

Hwang, R.N., Huang, C.Y. and Yang, C.L. (2016). Determinants and their causal relationships affecting the adoption of cloud computing in science and technology institutions, Innovation, 18(2): 164 - 190

Kiakojuri, D., Shamshirband, S., Anuar, N.B. and Abdullah, J. (2015). Analysis of social capital by using DEMATEL approach: the case of Islamic Azad University, Quality \& Quantity, 49, 1985 -1995.

Matthews, J, Croft, T, Lawson, D. and Waller, D. (2013), 'Evaluation of mathematics support centres: a literature review', Teaching Mathematics and Its Applications, 32, 43 - 52.

MacGillivray, H. L. (2008). Learning support in mathematics and statistics in Australian universities. A guide for the university sector. Queensland University of Technology. http://www.mathcentre.ac.uk/resources/uploaded/guide--altc-learning-support-in-maths-and-stats.pdf

MacGillivray, H.L. (2009). Learning support and students studying mathematics and statistics. Int. J. Math. Educ. Sci. Tech., 40, 455-472.

O’Sullivan, C., Mac an Bhaird, C., Fitzmaurice, O. and Ni Fhloinn, E. (2014). An Irish Mathematics Learning Support Network (IMLSN) report on student evaluation of mathematics learning support: insights from a large scale multi-institutional survey. http://eprints.maynoothuniversity.ie/6890/1/CMAB_IMLSNFinalReport.pdf

Perkin, G. Pell G. and Croft, T. (2007). The mathematics learning support centre at Loughborough University: staff and student perceptions of mathematical difficulties, Engineering Education, 2(1), 47 - 58

Ranjan, R. Chatterjee, P. and Chakraborty S. (2015). Evaluating performance of engineering department in Indian university using DEMATEL and compromise ranking models, Opsearch, 52(2): 307 - 328.

Si S, You X, Liu H, Ping, Z. (2018). DEMATEL technique: A systematic review of the state-of-the-art literature on methodologies and applications, Mathematical Problems in Engineering. https://www.hindawi.com/journals/mpe/2018/3696457/

Teng, J.Y. (2002). Project evaluation: Methods and applications. Taiwan, National Taiwan Ocean University.

Wilkins, L. (2015). Maybe we could just count the boxes of chocolates? Measuring the impact of Learning Development mathematics support for undergraduate students. Journal of Academic Language and Learning, 9(2), A91-A115 